\title{
Timing of preoperative patient teaching
}

\author{
Marybeth Lepczyk MSN RN CS \\ Gerontology Clinical Nurse Specialist Harper Hospital, Detrott
}

Edith Hunt Raleıgh PhD RN

Research Fellow. The University of Michigan, Ann Arbor

and Constance Rowley MEd RN

Case Manager, Medical Product Line Harper Hospital, Detrott, USA

LEPCZYK M, HUNT RALEIGH E \& ROWLEY C (1990) Joumal of Advanced

Nursing 15, 300-306

Timung of preoperative patient teaching

With the increasing cost of health care and the growing constraints made by third party payers, in-hospital time for preoperative teaching is quickly being reduced Seventy-two patients attended preoperative instruction either as an inpatient the day before surgery or as an outpatient 4-8 days before surgery Anxiety and knowledge levels were measured before and after class and the evening before surgery No differences were found between the groups on a measure of anxiety levels Both groups demonstrated a moderate anxiety level with no significant change over the testing period Using the knowledge pretest as a covariate, repeated measures analysis of variance suggested the knowledge gained with the class was significantly greater for the outpatient group than the inpatient group ( $P=0$ 018) There was also a significant positive relationship between the knowledge score and knowing someone who had cardiac surgery $(t=234, \mathrm{~d} f=66, P=0$ 022) The results suggest that it makes little difference whether patients receive information up to a week before surgery or just the day before, therefore, the more economical preadmission teaching may be the path of choice

\section{INTRODUCTION}

The soanng cost of health care has become the focus of national attention It is timely, therefore, that nurses evaluate their role in the delivery of nursing services to assure that care is provided in a safe, professional and costeffective manner This includes examining the standard of practice of a structured preoperative teaching programme for surgical patients

Some hospitals offer a teaching programme to patients before admission to the hospital and others offer it after

Correspondence Edith Hunt Ralezgh Research Fellow School of Nursing Unwoersity of Michigan $400 \mathrm{~N}$ Ingalls Ann Arbor, Michigan 48109, USA. admission, during the penod of the preoperative work-up The in-hospital preoperative penod is becoming increasingly shorter because of the changing nature of third party reimbursement Therefore, most institutions admit the patient the afternoon pnor to surgery (often as late as 1600 ), or in some elective cases, on the morning of surgery Because it is often difficult for the nurse to arrange a preoperative class in the limited time avallable, more hospltals may begin to provide preoperative teaching prior to admission With the current emphasis on shortening both the pre- and postoperative hospital stay, it is timely for nursing departments to review their preoperative teaching methods and institute changes as needed 
Patients who attend preoperative teaching classes are usually those who have decided they need and want the information offered (Johnson et al 1978) Studies have demonstrated that these patients do better postoperatively (Hartfield \& Cason 1981, Divine \& Cook 1983, Rice \& Johnson 1984), however, the issue of the best time for learning this information has not been adequately studied (Kıng \& Tarsitano 1982) Does the time at which patients receive the instruction (before or after admission) affect their anxiety level? Does it affect retention of information? The purpose of this study was to explore these questions using a sample of patients scheduled for cardiac surgery

\section{REVIEW OF LITERATURE AND CONCEPTUAL FRAMEWORK}

The cardiac surgery patient attending preoperative classes Is an adult learner Malcolm Knowles (1973) proposes characteristics of the adult learner that are pertinent to patient teaching (1) the adult is self-directed, (2) the adult has accumulated a reservoir of expenences that serve as a resource for learning, (3) the adult's readiness to learn is oriented to the developmental tasks of social roles, and (4) the adult desires immediate application of learning Adults may resist learning under conditions incongruent with their self-concept as autonomous individuals They are motivated to learn when they recognize a gap between what they know and what they want to know

These principles suggest several applications for patient teaching Patients should be allowed to articulate their own learning needs and make choices The adult's reservoir of accumulated knowledge supports the wisdom of group learning settings where adults can teach each other In addition, subject matter should be related to the learner's ability to succeed in his/her social roles The principle of immediate application suggests that adults are especially motivated to learn at tımes of crises

Other educational principles suggest methodologies that affect the retention of information by the adult learner in times of illness Combining written and verbal instructions has been demonstrated to be supenor to using either alone in producing retention (Green 1979) Supplementing oral instructions with written communication is an application of the education principle that information which is repeated will be retained and recalled more readily than information that is not repeated Written instructions can be referred to repeatedly by the patient The task for nurses and other health care professionals is to make available relevant, comprehensible and useful information at the time and place where it is more likely to motivate, enable or reinforce health behaviour $A$ time of immediate threat may not be conducive to retention

\section{Cardiac surgery}

Cardiac surgery may be classified as a crisis or threatening event for most patients, producing anxiety in response When faced with a potentially threatening event, the individual cognitively appraises the situation, weighing resources against the attributes of the stimulus If the situation is seen as threatening, anxiety is aroused and a second appraisal is made to determine the best way to cope with the threat The coping strategy used depends upon the results of the secondary appraisal Individuals who seek information about their surgery are coping by attempting to gain some control of the situation through knowledge which assists in another appraisal of the threat (Lazarus \& Folkman 1984)

Choice of a coping process depends in part on one's resources, which include health, energy, beliefs about God or control, commitments, problem-solving skills, social skills, social support, and material resources (Lazarus \& Folkman 1984) To assist patients in their coping behavlour, preoperative classes are offered to provide the information they seek Janis (1958) reported that providing information about the surgical event facilitates a process of mental 'rehearsal', enabling the individual to develop reality-based expectations and plans for coping with the perceived danger

Rakoczy (1977) found that cardiac surgery patients frequently described feelings of helplessness, fear of impairment, and fear of dying when initally confronted with the need for cardiac surgery Lazarus \& Averill (1972) described three factors which give nise to the feeling of helplessness, a major component of anxiety (I) the inability to interpret or give meaning to a situation, (2) the inability to anticipate events, and (3) uncertainty

Dunng this period of uncertainty, the nurse may best help patients by allowing them time to vent their concerns According to Rakoczy (1977), when these patients become resolved to the need for cardiac surgery, they seemed ready for structured preoperative education Although she identified the psychological phases that patients go through pror to surgery, she did not elaborate on the time frame for each of the phases

\section{Timing of teaching}

It has been suggested that the time penod between learning of the need for surgery and the actual surgery is a 
Table 1 Sample background questions
1

2

3

4

significant factor in determining preoperative anxiety level (Dumas \& Johnson 1972) Patients who learned that surgery was advisable a month or less before hospital admission had higher anxiety levels than those who knew of the need for surgery for more than a month $A$ time penod to assimilate information may be as important as the actual information Levesque et al (1984) compared preadmission preoperative teaching to postadmission preoperative teaching in a sample of 82 elective cholecystectomy patients The researchers were interested in the effect which timing of teaching had on anxiety and postoperative recovery Three groups were studied (1) preadmission instruction, (2) postadmission instruction and (3) no instruction (control) Groups were established over 2-week periods using a randomly chosen rotating schedule which was repeated 13 times Subjects were assigned to the current group as they were admitted There were no significant differences in anxiety scores and postoperative recovery between the two experimental groups

Chnstopherson \& Pfeiffer (1980) addressed the timing issue in their study of the relationship between timing of information, level of knowledge, and self-reported anxiety Their sample of 41 patients was randomly assigned to two groups, initially Group $1(n=11)$ read the preoperative teaching booklet $1-2$ days pror to surgery Group 2 $(n=18)$ read the booklet anywhere from 3 to 35 days preoperatively There were additional patients $(n=12)$ in each group who chose not to read the booklet These individuals were put in a third group retrospectively for analysis The resulting data indicated that whether the patient read the booklet 1-2 days preoperatively or 3-35 days preoperatively made little difference in the information recalled postoperatively Additionally, patients who received the teaching booklet 1-2 days preoperatively (group 1) expenenced less anxiety postoperatively
In summary, the literature suggests that sufficient time to assimilate information is important for the adult learner To date, the few studies which examined timing of preoperative instruction have been inconclusive, suggesting the need for further investigation For the purposes of this study, it was hypothesized that cardiac surgery patients who received a preoperative teaching programme prior to admission would have less anxiety and greater knowledge preoperatively than patients who received preoperative teaching after admission

\section{METHODS}

\section{Sample}

The convenence sample was selected from a population of patients who presented themselves for preoperative classes before coronary artery bypass surgery at two large metropolitan hospitals Groups 1 (from one hospital, $n=$ 32) received teaching 2-7 days prior to hospital admission Group 2 (from the other hospital, $n=42$ ) received teaching on the afternoon of hospital admission Seventy-four patients consented to participate Data were collected over 8 months Patients were excluded from the study based on the following critena (1) previous heart surgery, (2) other surgery in combination with the bypass surgery, (3) not fluent in written Enghsh, and (4) emergency surgery

\section{Measures}

\section{Background questionnaire}

This questionnaire was developed by the investigators to gather demographic data as well as data on the patient's sources of information regarding the surgery Sample questions are displayed in Table 1 
Heart surgery questionnaire

This questionnaire, also developed by the investigators, was used in three forms for the pretest and post-tests It consisted of 14 multiple choice questions in the following categones anatomy and physiology, procedures and policles, activity, and sensations Scores (the sum of correct responses) may range from 0 to 14 The questions remained the same in all three forms of the questionnaire, but their order was randomly changed Content validity was established by a panel of clinical nurse specialısts with expertise in cardiovascular nursing using the class objectives There was $100 \%$ agreement among panel members Test-retest reliability in a pilot of the pretest and post-test of the instruments using preoperative cardiac surgery patients $(n=20)$ yielded a correlation coefficient of 068 The test for internal consistency yielded Cronbach's alpha of 076

\section{State-Trait Anxiety Inventory (STAI)}

This inventory consists of 20 short statements regarding present feelings in a Likert format It has two forms state and trait The state form was used in this study Scores may range from 20 to 80 Original reliability of the STAI was tested with undergraduate college students Internal consistency coefficients of greater than 085 were reported by the authors (Speilberger et al 1970) In this study the Cronbach's alpha coefficient for internal consistency was 090

\section{Procedure}

Potential subjects were identified from scheduled admissions lists Patients in both groups were contacted by phone prior to class The study was explained and verbal consent obtained The patients who agreed to partic1pate were asked to come early to class to complete the questionnaires

When they arnved, the study was explained once again, and written consent was obtained Pnor to the class, the patients completed the background questionnaire and the frst heart sugery questionnaire and STAI They attended the class and afterward completed the second heart surgery questionnaire and STAI The evening of the preoperative day, all patients completed the third heart surgery questionnaire and STAI

\section{Preoperatioe class content}

The classes at the two hospitals were identical in content and teaching methods The class covered anatomy and physiology, pathology, the surgical procedure, preoperative and postoperative procedures, the intensive care unit environment, and sensation information as well as emotional and psychological reactions to surgery Patients and family members were encouraged to ask questions and express feelings and concerns Patients were given a booklet containing basic preoperative information and instructions for exercises The preadmission class was held 1 day each week and the postadmission class was held in the early afternoon of the admission day

\section{RESULTS}

The level of significance was preset at 005 The age of the subjects ranged from 32 to 75 years with a mean age of 591 years and a standard deviation of 931 There was a statistically significant difference in age between the preadmission $(\bar{X}=617)$ and postadmission $(\bar{X}=572)$ teaching groups (Table 2) Demographic characteristics of the participants are displayed in Table 2 The two groups were also compared on pretests of knowledge and anxiety Using chi-square or $t$-test analysis as appropriate, the two groups did not differ significantly on any demographic variable, other than age, nor did they differ on anxiety level as determined by STAI However, there were significant differences on the knowledge pretest (group $1, \bar{X}=1045$, group $2, \bar{X}=1203, t=-283, \mathrm{df}=71, P=0006$ )

\section{Anxıety}

It was proposed that the preadmission group would have less anxiety than the postadmission group Using repeated measures analysis of variance, this hypothesis was not supported The means of the two groups did not differ on any of the anxiety questionnaires, with means ranging from 403 to 442 on a scale of 20 to 80 (Table 3) This moderate level of anxiety was demonstrated by both groups at the start of preoperative teaching, and it did not change significantly after teaching or prior to surgery In addition, there was no significant relationship between the amount of anxiety and the length of time between learning of the need for surgery and the actual surgery Females had significantly higher anxiety scores than males $(t=-216$, $\mathrm{df}=56, P=0035$ )

\section{Knowledge}

It was also hypothesized that patients who recelved preoperative teaching prior to admission would have greater knowledge than patients who received preoperative teaching after admission, and that the preadmission group would retain more knowledge than the postadmission group Because there was a significant difference between 
Table 2 Demographic characteristics of the participants
$* t=212 \mathrm{df}=72 \quad P=037$

"No significant differences using chi-square analysıs

\begin{tabular}{|c|c|c|c|c|}
\hline Characteristic & Category & $\begin{array}{l}\text { Preadm } \\
\text { Group } 1\end{array}$ & $\begin{array}{l}\text { Postadm } \\
\text { Group } 2\end{array}$ & Total \\
\hline Age $^{*}$ & & $\begin{array}{r}\bar{X}=617 \\
\mathrm{sd}=70\end{array}$ & $\begin{array}{r}\bar{x}=572 \\
\text { sd }=104\end{array}$ & \\
\hline \multirow[t]{2}{*}{ Gender ${ }^{* *}$} & Male & 28 & 31 & 59 \\
\hline & Female & 4 & 11 & 15 \\
\hline \multirow{3}{*}{ Ethniaty ${ }^{* *}$} & Black & 2 & 5 & 7 \\
\hline & White & 29 & 37 & 66 \\
\hline & Latino & 1 & 0 & 1 \\
\hline \multirow[t]{5}{*}{ Education ${ }^{* *}$} & 8th grade or less & 5 & 5 & 10 \\
\hline & $9-11$ grade & 3 & 11 & 14 \\
\hline & High school graduate & 11 & 13 & 24 \\
\hline & $1-3$ years post-HS & 10 & 10 & 20 \\
\hline & College degree(s) & 3 & 3 & 6 \\
\hline \multirow[t]{8}{*}{ Occupation ${ }^{* *}$} & Professional & 4 & 5 & 9 \\
\hline & Managerial & 4 & 3 & 7 \\
\hline & Clenical & 1 & 3 & 4 \\
\hline & Skalled worker & 11 & 12 & 23 \\
\hline & Semi-skılled & 1 & 8 & 9 \\
\hline & Labourer & 1 & 0 & 1 \\
\hline & Homemaker & 1 & 6 & 7 \\
\hline & Other & 9 & 5 & 14 \\
\hline
\end{tabular}

Table 3 Mean anxiety scores by groups

\begin{tabular}{lcccc}
\hline & & \multicolumn{2}{c}{ Group } & \\
\cline { 3 - 4 } & & 1 & 2 & Plevel \\
\hline \multirow{2}{*}{ Mean } & Test 1 & 403 & 442 & 0375 \\
& & $(103)^{*}$ & $(106)$ & \\
Anxiety & Test 2 & 422 & 439 & 0856 \\
& & $(114)$ & $(122)$ & \\
Scores & Test 3 & 415 & 434 & 0604 \\
& & $(107)$ & $(105)$ & \\
\hline
\end{tabular}

*Standard deviations are given in parentheses

the two groups on the knowledge pretest, the pretest was used as a covariate Using repeated measures analysis of variance and the pretest as a covariate, this hypothesis was supported at the 0018 level of significance. The knowledge gained with class was significantly greater for the preadmission group than the postadmission group, however, this was a small practical difference (Figure 1)
Also there was a significant relationship between the pretest knowledge score and knowing someone who had cardiac surgery $(t=234, \mathrm{df}=66, P=0022)$ The 58 patients who reported knowing someone who had cardiac surgery scored higher in knowledge than those who did not, however, knowing someone with cardiac surgery was not related to the anxiety scores Additionally, 50 patients $(81 \%)$ reported seekung knowledge when told of the need for surgery

\section{DISCUSSION}

There was no relationship found between the time chosen for the preoperative teaching and the anxiety level of the patients Based on the STAl scores, the patients exhibited a moderate level of anxiety before and after teaching and on the evening before surgery Considening the senousness of the surgery, it may be unrealistic to expect the anxiety level to be reduced

Anxiety is characterized by the individual's inability to specify the source of threat or the object that is threatened (May 1977) It is often manifested by general restlessness, 


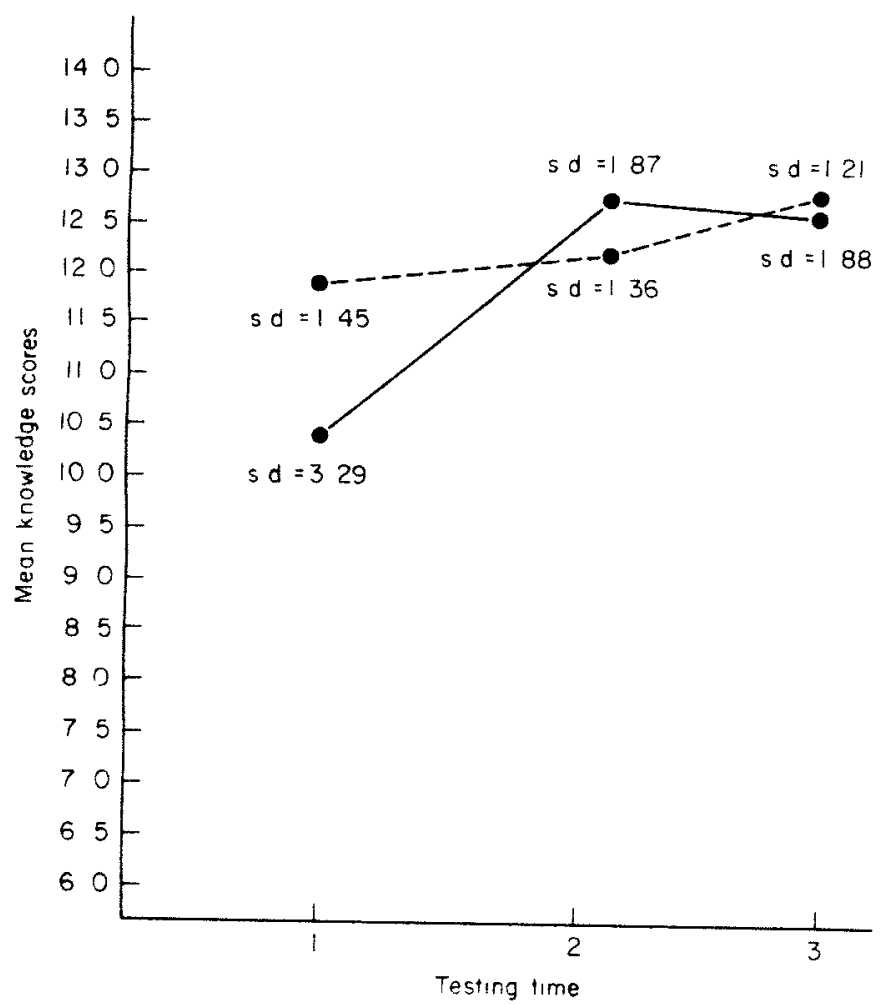

Figure 1 Heart surgery questionnarre scores by group over time $-=$ preadmission group $1,---=$ postadmission group 2 , $\mathrm{s} \mathrm{d}=$ standard deviation

sleep disturbances, and purposeless movements (Yocum 1984) Conversely, the major charactenstic of fear is the ability of the individual to identify the specific source and object of the threat (May 1977) Behavioural manifestations of fear (1 e increased alertness and concentration) subside shortly after the threat has been removed The patients in our study sample did have a specific threat (coronary artery surgery) that could have been identified as the source of their fear It may be fear is a more appropnate variable than anxiety for study

Another point to consider is that the participants may have been largely 'knowledge-seekers' as indicated by the $81 \%$ who sought information after learning of the need for surgery This may explain the moderate level of anxiety demonstrated on the pretest and the lack of significant changes in the anxiety levels As discussed in the literature review, knowledge-seekers cope by obtaining information If they had been denied information, perhaps a significant change in anxiety scores would have occurred

The study lacks significant results, a situation which is similar to other studies in this area which have also been inconsistent in their findings Levesque et al (1984) found significant differences in preoperative anxiety between preadmission and postadmission teaching groups while
Christopherson \& Pfeiffer (1980) found no significant differences Lindeman \& Van Aernam (1971) demonstrated positive effects of preoperative teaching while Rice \& Johnson (1984) found no significant differences between groups receiving written preadmission preparation or eveof-admission preparation

The preadmission group in this study did gain more knowledge by attending class, however, the postadmission teaching group came to class with more information The difference in level of knowledge before class may be explained by the quasi-experimental design, the patients at one hospital may have had access to more information pnor to class than the patients at the other hospital

However, the gain in knowledge by the preadmission group may not be of practical significance because both groups scored well on the pretest Retention was high in both groups This is especially important since the preadmission group had up to a week to forget or assimilate information and the postadmission group had almost no time to assimilate information Additionally, the postadmission group was faced with the immediate threat, which is thought not to be conducive to retention

The principle of written and verbal information for adult learning may be pertinent here Those in the preadmission group had up to a week to read the materials given to them and assimilate the information Those in the postadmission group may have received similar written material from their physicians This could account for their high level of knowledge on the pretest A limitation of this study was that specific data regarding the type and amount of information given by the physicians were not obtained

It may be that former cardiac surgery patients are an important source of information for preoperative heart surgery patients They seemed to have been significant in increasing knowledge scores of patients in both groups This may be because of prolonged contact with a previous patient through social interaction or work, or it may be that hearing the information from a peer has significant impact on memory

These results suggest that it makes no difference whether patients receive information up to a week before surgery or just the day before Yet, teaching patients prior to admission is fast becoming an economic necessity Another study (Ruce \& Johnson 1984) has demonstrated that patients can learn expected behaviours, such as postoperative exercises, prior to admission If patients are not adversely affected by receiving the surgical information up to a week before admission and if they retain almost $100 \%$ of the information learned, this would seem to be a prudent and beneficial direction to take Not only is it more costeffective in terms of patient hospital days, but it is more 
cost-effective when scheduling nursing time for patient instruction Less nursing time is required for a single weekly class than for five a week Based on the findings of this study, it may be concluded that nurses and patients may select a mutually convenient time for the preoperative class

\section{CONCLUSION}

This study did not demonstrate the expected results regarding the timing of the preoperative teaching programme The two groups had similar preoperative anxiety and knowledge levels, therefore, no conclusion can be drawn about the timing of preoperative teaching Based on current knowledge, there are no gurdelınes to help establish the best time for the preoperative instruction class While there will always be some patients who have difficulty attending an outpatient class, the outpatient class may be the only option for the nurse and patient because of the reduced time in the hospital before surgery Another option to consider is mailing preoperative information to the patient's home This may be even more cost-effective and enable the patients to learn at their own pace The information could be briefly reviewed after the patient is admitted Further research is needed to evaluate this option

Formalizing the role of former cardiac surgery patients as peer support givers for preoperative cardiac surgery patients may provide an important adjunct to preoperative teaching in this group This option also requires further research

\section{Acknowledgements}

The order of authorship was arbitrary The authors would like to acknowledge the assistance of Lula Lester MSN RN, Mary Lee Van Keuren MSN RN, Kathleen West MSN RN and Kathleen Zimnickı MSN RN, for their assistance in data collection

This study was supported in part by a grant from the Amencan Heart Association of Michigan, Professional Nurses Research Grand Award

\section{References}

Christopherson B \& Pfeiffer C (1980) Varying the timung of information to alter preoperative anxiety and postoperative recovery in cardiac surgery patients Heart and Lung 9(5), 855-861
Divine E \& Cook R (1983) A meta-analytic analysis of psychoeducational interventions on length of post-surgical hospital stay Nursing Research 32(5), 267-274

Dumas R \& Johnson B (1972) Research in nursing practice a review of five clinical experiments International Joumal of Nursing Studies 9, 137

Green L (1979) Education strategies to improve compliance with therapeutic and preventive regimes the recent evidence In Complance in Health Care (Haynes B, Taylor D \& Sackett D, eds), Johns Hopkins University Press, Baltımore

Hartfield M \& Cason C (1981) Effect of information on emotional responses during barium enema Nursing Research 30, 151-155

Janis K (1958) Psychological Stress Psychoanalytical and Behavioral Studies of Surgical Patients John Wiley, New York

Johnson J, Rice V , Fuller S \& Endress P (1978) Sensory information, instruction in a coping strategy and recovery from surgery Research in Nursing and Health 1, 4-17

King I \& Tarsitano B (1982) The effect of structured and unstructured preoperative teaching a replication Nursing Research 31, 324-329

Knowles M (1973) The Adult Learner A Neglected Species 2nd edn Gulf, Houston

Lazarus R \& Folkman S (1984) Stress, Appraisal and Coping Springer, New York.

Lazarus R \& Averill J (1972) Emotion and cognition with special reference to anxiety In Anxiety Current Trends in Theory and Research (Spellberger CD ed), Academic Press, New York

Levesque L , Grenier R , Kerouac S \& Reidy M (1984) Evaluation of a presurgical group program given at two different times Research in Nursing and Health 7, 227-236

Lindeman C \& Van Aernam B (1971) Nursing intervention with the presurgical patient the effects of structured and unstructured preoperative teaching Nursing Research 20, 319-332

May R (1977) The Meaning of Anxiety, revised edition W W Norton, New York

Rakoczy M (1977) The thoughts and feelings of patients in the waiting period pnor to cardiac surgery Heart and Lung 6(2), 280-287

Ruce V \& Johnson J (1984) Preadmission self-instruction booklets, postadmission exercise performance and teaching time Nursing Research 33(3), 147-151

Spielberger C, Gorsuch R \& Lushene R (1970) State-Tratt Anxiety Inventory Consulting Psychologist Press, Palo Alto

Yocum C (1984) The differentiation of fear and anxiety In Classification of Nursing Diagnosis Proceedings of the Fifth National Conference (Kim M J, McFarland GK \& McLane A M eds), CV Mosby, St Lours, pp 352-355 
This document is a scanned copy of a printed document. No warranty is given about the accuracy of the copy. Users should refer to the original published version of the material. 